\title{
Trends in Educational Research About Online Learning in Chinese Universities: A Systematic Literature Review (2020-2021)
}

\author{
Yulan Luo ${ }^{1, \mathrm{a}}$
}

${ }^{1}$ Jimei University
${ }^{a} \underline{412956932 @ q q . c o m}$

\begin{abstract}
Due to the disturbance caused by the COVID-19 pandemic, schools worldwide were once shut down. It was online learning that made it possible for students worldwide to continue the practice of education. The topic of e-learning has therefore been intensely discussed recently. This paper serves as a systematic literature review to draw an outline of current researches about Online Learning in Chinese Universities (2020-2021). It is discovered that online learning is generally accepted by students and teachers; curriculum adaption and creating interaction is pivotal; and that blended learning will continue to be heatedly discussed.
\end{abstract}

Keywords: online learning, Chinese higher education, college students, teachers, curriculum, blended learning.

\section{INTRODUCTION}

From the perspective of research fields, the most discussed topic is blended learning, while there is a lack of empirical research on online teaching training for teachers. As for research methods, most of the current researches are based on quantitative analysis in the form of online surveys. A few researches have used a combined method of both online survey and interview, while pure qualitative study is few and far between. This paper aims at gathering research results of online learning in Chinese universities from 2020 to 2021 in the hope of providing convenience as well as inspirations for the following researchers.

\section{PERSPECTIVES FROM VARIOUS ASPECTS ON THE CURRENT EDUCATIONAL SITUATION}

\subsection{Perspectives from students}

\subsubsection{Obstacles students met in online learning}

Based on an analysis on the data collected from homepages of 2688 Chinese universities in micro-blog, for some students in remote rural areas with unstable network and those from poor families, there are still practical problems such as lacking electronic devices, no wireless network at home, and the inability to afford high cost of data flow[1]. Whereas, according to another online questionnaire survey in Shanghai City, the digital gap between rural and urban areas has narrowed, which can be seen from the fact that students with household registration in rural areas or towns are buying more new computers and broadband than urban students[2], indicating that great breakthroughs have been made in the construction of educational information infrastructure in remote rural areas in recent years and the access to the internet is not any more a major obstacle to online learning for Chinese college students.

Similarly, the quality of the network is not considered as a major concern for them, indicating that the technology related to online learning is relatively stable and mature, according to the outcome of an online questionnaire survey about undergraduates in Shenyang province. Whereas, the biggest impediment derives from students themselves, namely their inner motivation, self-discipline and cognitive ability [3]. 


\subsubsection{Factors that influence students learning experience}

Firstly, individual characteristics of college students have an impact on online learning experience. In terms of area difference, students from universities in the east have the best online learning experience, followed by those from universities in the middle regions, while those from the west have the least satisfaction, though the differences are not obvious [4]. This may be the result of digital gap among the three regions. In terms of gender, female college students are slightly more satisfied with online learning than their counterparts [4]. The reason is that in the process of online learning, female students cognitive input, behavioral input, and emotional input are slightly higher than their male counterparts, although male students do have more social interaction input [17]. In terms of disciplines, liberal arts students experience slightly better than students majoring in science, engineering, and medicine [4].

Secondly, teaching and assessment process also affects students' performance: the online learning experience of college students is affected by the assessment process, which is composed of material previewing, in-class quiz and after-class homework. A student in the interview reflected that the online assessment process was much more complex than its off-line counterpart, and that he as well as his classmates was bewildered. In the teaching process, a well-interactive teaching design has a positive effect on students' learning experience [4].

Above all, students' online learning experience is most affected by teachers' proficiency in using all kinds of online teaching tools. When teachers for the first time tried the online teaching tools, they checked again and again with students about the clarity of their voices and the fluency of the videos, which sometimes were considered a waste of time and made students impatient [4].

\subsubsection{Attitudes toward online learning}

In an online questionnaire survey using sampling method, It is discovered that among all forms of online learning, live streaming and interactive class enjoys the biggest popularity[5]. It may be attributed to the availability of online interaction in live streaming classes. However, this form of interaction cannot compare to face-to-face interaction, and there are still quiet a few students reporting that the sense of interaction is not strong enough in live streaming classes[7]. Other than that, students are generally satisfied with online learning. According to a survey results, more than $50 \%$ of students are satisfied or very satisfied with online teaching [5], which shares a similar result in another survey conducted by Peng, Jiang and
Zhou [7]. Whereas, students entertain little willingness to continue online learning although are grateful for teachers' hard work in adapting to online teaching. There is an earnest expectation among them of returning schools[1].

\subsection{Perspectives from Teachers}

\subsubsection{Attitudes towards online teaching}

Online teaching has been accepted and welcomed by most college teachers. According to a national survey on online teaching conducted by National Union of Quality Assurance Institutions of Higher Education, in the context of post-pandemic future, $76.5 \%$ college teachers are willing to adopt blended teaching, or online teaching combined with offline teaching, and $49.5 \%$ college teachers are willing to continue online teaching, whereas teachers who rejected continuing online teaching only account for $23.1 \%$ [6] .

Teachers have met tremendous obstacles in transiting to online teaching. According to $\mathrm{Wu}$ and Li's research result, the most difficult part for teachers is changing teaching strategies and methods, followed by changing old teaching habits, changing teaching concept, learning to use different types of teaching technology products and increased working burden [18].

From teachers' perspective, online platforms has significant room for improvement. Many teachers request to improve the functions of the platform, improve the speed and stability of the network, and strengthen online technical services and support[6]. Besides, there is also an area disparity in teachers' request for network improvement, which is similar to the regional difference that influences student's online learning experience. Teachers in the west regions have the strongest request for network improvement, followed by those in middle regions, and those in east regions are relatively ease about network improvement [6].

The also survey suggests that college teachers commonly agree that students need to improve their online learning behavior. The main reason is that the characteristics of online teaching itself put forward higher requirements for students' learning ability and good learning habits [6].

\subsubsection{Training: to achieve digital competence}

During the pandemic, college students are the group of students that spent the longest time in online learning. Therefore, college teachers should receive systematic training that helps them achieve digital competence. According to the investigation report on online teaching of college teachers during epidemic period, the proportion of college teachers conducting online 
teaching has increased from $20.43 \%$ to $97.19 \%$. Among them, $81.65 \%$ of teachers have received online teaching training, and more than $76 \%$ of teachers give positive evaluation to the teaching method training and technical method training. Nevertheless, "adapting teaching strategies and teaching methods" is still the biggest challenge for college teachers in online teaching, and $80 \%$ of teachers hope to further strengthen teacher teaching training [16]. The survey conducted by $\mathrm{Wu}$ and Shen also shows a strong demand of teacher training: $50.4 \%$ of involved college teachers think they need further training on online instructional design. $48.6 \%$ of them think interaction between teacher and students is unsatisfactory. $29.4 \%$ of them think online teaching is of low efficiency. $16.3 \%$ of them believe that they "cannot adjust their teaching methods well according to the characteristics of online teaching" [5].

The "Double First-Class" universities have initiated practice and model innovation of online teaching and training for faculty members. They advocate three concepts as the essence of teachers' training, namely teaching democracy, collaborative teaching, and scholarship of teaching. Teaching democracy suggests that in training teachers are not only passive receivers but also active developers, leaders and cooperators who have the right and freedom to conduct teaching communication and academic discussion. Collaborative teaching means in designing online classes, teachers should create a mechanism conducive to collaborate for teachers and students. Scholarship of teaching requires teachers to put promote the integration of teaching and research. These firs-rate schools also promote the basic teachers training in both synchronous and asynchronous teaching. Besides, micro class rehearsals and real class are conducted in the process of teacher training [16].

Online teaching and training is not only an emergency response, but also a new starting point for the development of online teaching in the post-epidemic era. How to integrate online teaching and training into regular teacher development in the post-epidemic era is a major issue to concern in order to effectively link currently unconventional measures with the development of future educational informationization [16].

\subsection{Curriculum}

\subsubsection{Course adjustment}

Liberal-arts curriculum is more adaptable than science and engineering curriculum for which experimental equipment is indispensable. However, many universities do not let this difficulty impede its teaching process. Take Northeast Petroleum University as an example, mechanical design, manufacturing and automation major requires students to conduct lots of experiments which was out of the question in the remote learning condition. To reverse the adverse conditions, teachers took the initiative to design an online experimental teaching scheme using cloud interaction and virtual simulation, and efficiently complete the experimental teaching task[8].

\subsubsection{Creating interaction}

The distinguish characteristic of online learning is that teaching and learning are separated in time and space, which determines the pivotal role of media-mediated interaction in remote teaching. Interaction in online courses is a key factor that influences students' learning engagement [9].

\subsubsection{Hypervideo}

From the perspective of time dimension, online learning interaction can be divided into synchronous interaction and asynchronous interaction. Live streaming is the most adopted form of synchronous interaction, which is able to keep learners enthusiastic but less flexible in time. Asynchronous interaction is mostly in the form of text forums, which enable flexible and large-scale learning but it has long feedback cycles and weakens learners' sense of social presence, thus reducing learners' interactions.

To save the cost and enlarge the scale of online learning requires combining the benefits of both synchronous and asynchronous interaction [10].

Hypervideo is alleged to well serve this purpose. Hypervideo is defined as video with hyperlinks, which allows navigation control and enable users to switch to additional materials; it is also able to integrate individual or collaborative annotation and automated or manual feedback. It means that hypervideo can be watched through a non-linear patch that is opposite to the manner of watching a traditional video[11].

In this way, it focuses on the intention of users and changes them from passive receivers to active learners. It also optimizes optimize learner's learning experience by increasing interactions and promoting reflection. In conclusion, videos in online learning only serves as a medium of knowledge transmission while the interactive characteristic of hypervideo makes it a cognitive and social tool to promote learning [10].

\subsubsection{Embedded questions in online videos}

As a common interactive method in online learning video course, embedded questions can help improve learning effect and learning participation. Depending on the content and forms of the feedback, it can be divided into three types: right answer feedback, explained answer feedback and index point feedback. Depending on the content and forms of the feedback, it can be divided into three types: right answer feedback, 
explained answer feedback and index point feedback [12].

\section{TRENDS IN ONLINE LEARNING}

\subsection{Blended Learning}

Recently, blended learning (BL), which is increasingly utilized in higher education, has been intensely discussed, especially during the pandemic. It is expected that in the post COVID-19 future, even when students return to the physical classroom, the trend toward blended learning will still continue [13]

Therefore, it is reasonable to predict that BL will continue to be a hot academic topic in the near future.

Currently the majority of definitions of BL refer to a combination of face-to-face and online instruction. In Cronje's view, however, other elements like context, theory, method and technology should not be excluded in the definition of BL. He thus define blended learning as "the appropriate use of a mix of theories, methods and technologies to optimize learning in a given context" [14].

Based on the analysis of Zhang, research hotspots of blended learning in China can be roughly divided into the following five aspects: basic theory research of blended learning, blended teaching design and practice, online platforms that support blended learning, BL resource construction and BL performance monitoring [15].

He also spots some deficiencies in the current BL research. First comes the lack of empirical study. From the perspective of literature quantity, the number of articles on basic theory construction is far greater than empirical research, and the theoretical research results account for more than a half. Secondly, research object is far from diversified. More than $80 \%$ of the research results come from the field of higher education; only a few related researches are found in the field of basic education, continuing education and enterprise training. Lastly, little research paper has mentioned the role of supervision in blended learning, and a lack of supervision may make students feel at lost in online learning [15].

\section{CONCLUSION}

Both students and teachers have met great obstacles in shifting to online learning. For college students, the digital gap between students in rural and urban areas has narrowed and internet connection is not a major challenge in online learning. Instead, students' inner factors are the biggest impediment. Factors that influence their learning experience include individual characteristics, teaching and assessment process, and teachers' digital proficiency. Although students are generally satisfied with online learning, their willingness to continue this practice is rather low.

As for college teachers, most of them hold a positive view of online teaching and are willing to adopt blended teaching in the post-pandemic future. The most difficult part for them is changing teaching strategies and methods and they have a strong demand for training to achieve digital competence.

Online learning calls for curriculum redesign. Some science and engineering curriculum which require practical experiments have been adapted to online learning by providing virtual simulation. Interaction is a pivotal part in online classes. Hypervideo and embedded questions in online videos are thought to be feasible measures to increase online interaction.

Online learning will live on the form of blended learning (BL) in the post-pandemic future. Hotspots and deficiencies in the current BL research are as generalized above.

\section{AKNOWLEDGMENTS}

Sincere gratitude goes to Miss Qiu and Mr. Chi Chennai who have provided assistance in writing this paper.

\section{REFERENCES}

[1] JIA Wenjun GUO Yuting ZHAO Zening, Clustering Analysis of College Students'Online Learning Experience

[2] Guo Jiao, The Evolution of Digital divide: from Access to Engagement-Based on the Undergraduate Online Learning Survey during Covid-19

[3] An Yuxin, Wang Yongdong, The Research on the Learning Obstacles and Learning Effects of College Students under the Online Teaching Mode.

[4] Chen Wuyuan, Jia Wenjun, Research on Contributing Factors of University Students' Online Learning Experience

[5] Wu Daguang, Shen Zhonghua. Rational thinking of online teaching in colleges and universities in China - - Based on the empirical investigation of six undergraduate colleges and universities [J].Educational science, 2020,36(02): 1-8.

[6] Zheng Hong, Xie Zuoxu, Wang Jing.Research on online teaching attitude of college teachers in post-epidemic era [J].Journal of East China Normal University (Education Science Edition ), 2020,38(07): 54-64.

[7] Peng Kui 'an, Jiang Chunyan, Zhou Wenwei. Research on the Satisfaction of College Students ' 
Online Teaching Platform [J]. Science and Technology, 2021 ( 25 ) : 95-97

[8] Zhao Hai, He Fujun, and Wang Suling. Exploration and practice of online teaching during the professional epidemic of machine in Northeast Petroleum University $[\mathrm{J}]$. Heilongjiang Education ( theory and practice ), 2021 (08): $65-67$

[9] Wang Zhijun.The essence and related concepts of ' teaching interaction' in distance education [J].Electrified education research, 2016, 37(04): 36-41.

[10] Zhang Jingjing, Niu Xiaojie, Yao Ziming, Zheng Qinhua.Experimental study on ' quasi ' synchronous video interaction in asynchronous online learning [J].Distance Education Journal, 2021,39(03): 52-64.

[11] Sauli F, Cattaneo A, van der Meij H. Hypervideo for educational purposes: a literature review on a multifaceted technological tool [J]. Technology, pedagogy and education, 2018, 27(1): 115-134.

[12] Han Xiaoling, Sun Bowen, Li Fengqing.Research on the influence of online learning video item feedback on learning effect [J].Distance Education Journal, 2020,38(06): 62-72.

[13] Singh, Harvey. "Building Effective Blended Learning Programs. " Challenges and Opportunities for the Global Implementation of E-Learning Frameworks, 2021, pp. 15 - 23., doi:10.4018/978-1-7998-7607-6.ch002.

[14] Cronje, Johannes. “Towards a New Definition of Blended Learning. " Electronic Journal of e-Learning, vol. 18, no. 2, 2020, doi:10.34190/ejel.20.18.2.001.

[15] Zhang Huainan. Research status and development trend of blended learning in China [J].Chinese medical education technology, 2019, 33(01) : 12-18.

[16] Li Ying, Tang Xiaoyong. ' Double First-Class ' College Teachers ' Online Teaching Training Practice and Mode Innovation [J/OL]. Journal of Southwest Jiaotong University (Social Sciences Edition), 2021 (05): 126-134 [2021-09-28].

[17] Yang Mei. Research on College Students ' Learning Engagement and Its Influencing Factors in Online Learning Environment [D]. Huazhong Normal University, 2020.

[18] Wu Daguang, Li Wen. Stage characteristics of large-scale online teaching in Chinese colleges and universities - An empirical study based on questionnaire survey of students, teachers and educational administrators [J]. Journal of East China Normal University (Education Science Edition), 2020,38(07): 1-30. 